\title{
Supercritical Water Oxidation of Coal Gasification Wastewater
}

\author{
Laisheng Wang ${ }^{1, a}$, Shuzhong Wang ${ }^{2, b}$ Yuzhen Wang ${ }^{3, c}$ and Yanhui $\mathrm{Li}^{4, \mathrm{~d}}$ \\ ${ }^{1,2,4}$ Key Laboratory of Thermo-Fluid Science and Engineering of Ministry of Education, School of \\ Energy and Power Engineering, Xi'an Jiaotong University, Xi'an, Shaanxi, China \\ ${ }^{3}$ Faculty of Printing and Packaging Engineering, Xi'an University of Technology, Xi'an Shaanxi, \\ China
}

awls512@stu.xjtu.edu.cn, ${ }^{\mathrm{a}}$ SZWang@aliyun.com, ${ }^{\mathrm{c}}$ yzwangxjtu@163.com, ${ }^{\mathrm{d}}$ liyanhuiyu@163.com

Keywords: Supercritical water oxidation, Coal gasification wastewater

Abstract. The sludge produced by biochemical treatment process of coal gasification wastewater contains large amount of phenol and tar, it is difficult to be degraded by conventional methods. Supercritical water oxidation (SCWO) technique was carried out for biochemical sludge from coal gasification wastewater treatment. The effect of temperature, pressure, oxidation ratio and reaction time was studied and the operation parameters were optimized. Results showed that higher temperature and oxidation ratio, longer reaction time effectively promoted the pollutants removal, while the effect of pressure was little. For a biochemical sludge with moisture content of $88 \%$, the $\mathrm{COD}$ and $\mathrm{NH}_{3}-\mathrm{N}$ in effluent were 42 and $5 \mathrm{mg} / \mathrm{L}$, respectively and the concentration of volatile phenol was below the limit of detection when treated at $873 \mathrm{~K}, 25 \mathrm{MPa}$, oxidation ratio of 3.5 and reaction time of $60 \mathrm{~s}$. The effluent quality can reach the national wastewater discharge standard I of GB 8978-1996. The study provided a new idea for the treatment of refractory sludge containing high concentration of tar and phenol.

\section{Introduction}

Coal gasification technology has been widely developed with the adjustment of the structure of energy sources industry. Lurgi pressurized gasification technology is currently used technology for the advantages of high adaptability of coal and low cost, but it will produce a large amount of coal gasification wastewater which contains much refractory material such as phenol and ammonia at all. Recently, the method to treat the coal gasification wastewater is pretreatment-biochemical treatment-deep processing. A large number of sludge will be produced during the biochemical processes. It will produce about $3 \sim 4$ tons of mud when dealing with 10000 tons of wastewater. This kind of sludge is hazardous waste for that it contains poisonous and harmful compounds, such as phenols and PAHs, so that it must be strictly disposed [1].

Supercritical water oxidation (SCWO) technology is a kind of environmental friendly, efficient technology which can deal with organic wastewater developed in the $1980 \mathrm{~s}$. It has many significant advantages, such as high efficiency, thorough reaction and no secondary pollution, because of the special properties of supercritical water ( $\mathrm{SCW}, T \geq 647 \mathrm{~K}$ and $P \geq 22.12 \mathrm{MPa}$ ) [2]. It was considered as the most efficient method for the treatment of municipal sludge, landfill leachate and some of the industrial wastewaters [3].

In this study, we carried out the SCWO experiments of coal gasification wastewater by a continuous flow SCWO experimental system. We studied the influence of some important operation parameters on the destruction of COD NH3-N and volatile phenol in SCWO reaction. The provided information of the study is expected to be valuable for guiding the design of SCWO reactor to treat the coal gasification wastewater biochemical sludge. 


\section{Materials and methods}

Material. We used $30 \mathrm{wt} \%$ hydrogen peroxide as oxidant in this study. The coal gasification wastewater was collected from a coal gasification plant located in Henan province. The characters of the sludge are as follow: COD is $30000 \mathrm{mg} / \mathrm{L}, \mathrm{NH}_{3}-\mathrm{N}$ is $30 \mathrm{mg} / \mathrm{L}$ and the volatile phenol is $22 \mathrm{mg} / \mathrm{L}$. Apparatuses. In this work, a treatment of coal gasification wastewater was carried out by a continuous flow SCWO experimental system. The system and the procedure are as follows in Fig. 1

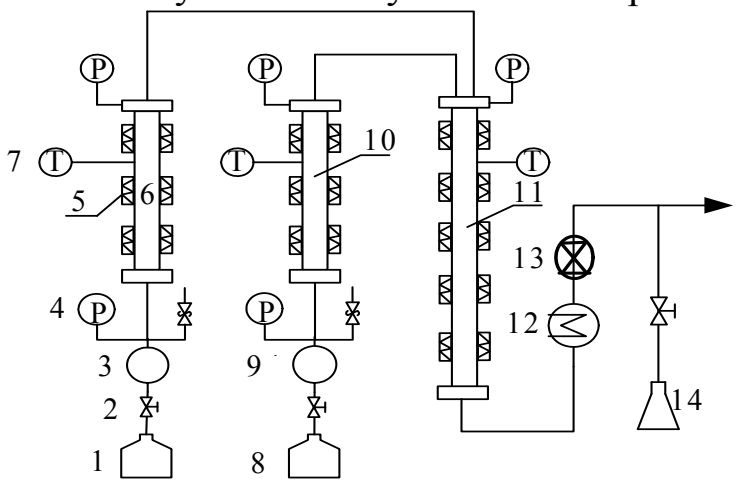

1 - the sludge storage tank; 2 - check valve; 3 - waste water pump; 4 - pressure gauge; 5 - heating device; 6 sludge preheater; 7 - the temperature measuring point of thermocouple; 8 - hydrogen peroxide tank; 9 - hydrogen peroxide pump; 10 - hydrogen peroxide preheater; 11 - reactor; 12 - cooler; 13 - back pressure valve; 14 - conical flask

Fig.1 System of the continuous SCWO reaction system

The design temperature and pressure of the reactor are $923 \mathrm{~K}$ and $28 \mathrm{MPa}$. The reaction tube is covered by thermal barrier, and it is heated by electrically heated wire. We will get the required reaction temperature by thermocouple temperature monitoring and the temperature controller. We use a high-pressure plunger pump to increase the pressure of the reactor. The fluid would be cooled to normal temperature by the cooler and the outlet pressure would be adjusted to the atmospheric pressure by back pressure valve.

Analysis method. COD of liquid products were determined via a multiparameter water analyzer (Model NOVA60) with individual Merck cell. The $\mathrm{pH}$ of the samples was analyzed in a Sartorius Professional Meter (PP-15, Germany).

Calculation method. COD removal efficiency $\eta$ is defined as follows:

$$
\eta(\%)=\left[1-\frac{[C O D]_{\text {pro }}}{[C O D]_{\text {raw }}} \times\left(-\frac{Q_{1}+Q_{2}}{Q_{2}}\right) \times 100 \%\right]
$$

where $[\mathrm{COD}]$ raw were the COD of the raw wastewater $(\mathrm{mg} / \mathrm{L})[\mathrm{COD}]$ pro were the COD of the reaction products. $\mathrm{Q}_{1}$ and $\mathrm{Q}_{2}$ represented the volume of wastewater and $\mathrm{H}_{2} \mathrm{O}_{2}$ solution $(\mathrm{mL})$ correspondingly which were obtained by a graduated cylinder.

\section{Results and discussion}

The effect of temperature to treatment of wastewater by SCWO. In order to study the effect of temperature, the SCWO experiments of the wastewater were conducted at fixed pressure $(P)$ of 25 $\mathrm{MPa}$ and constant oxidation coefficient $(\alpha)$ of 2.5 , the reaction time $(t)$ of $60 \mathrm{~s}$ and the temperature $(T)$ were changed from $823 \mathrm{~K}, 853 \mathrm{~K}, 893 \mathrm{~K}$. Each experiment repeated three times and the average result was plotted as the final value. The results are showed in Fig. 2. 




Fig. 2 Influences of temperature on treatment effeciency of biochemical sludge from coal gasification wastewater

As we can see from the Fig. 2, the removal rate of NH3-N, COD were affected by temperature significantly, and it rose with the rose of the temperature. The COD, NH3-N and volatile phenol were 120,5 and $0.03 \mathrm{mg} / \mathrm{L}$ at the temperature of $823 \mathrm{~K}$, and the removal rate were $99.6 \%, 94.82 \%$ and $99.93 \%$. But when the temperature were $853 \mathrm{~K}$, the COD, NH3-N and volatile phenol were 55,1 , and $0.01 \mathrm{mg} / \mathrm{L}$ and the removal rate were $99.82 \%, 96.67 \%, 99.95 \%$. Finally, we chose $580^{\circ} \mathrm{C}$ as the operating temperature considering ensuring water quality and reducing energy consumption. The influence of temperature to the COD and NH3-N removal rate are important. The reason is that most of the organic of the biochemical sludge are benzodiazepines material, and it needs more energy to be decomposed [4]. There are two aspects about the influence of temperature on the removal of the pollutant: first, the reaction activation molecule increase with the rise of the temperature; second, the rise of the temperature is helpful for the generation of $\bullet \mathrm{OH}$ radicals [5].

In order to analyze the ingredients of the products after SCWO, we analyzed the ingredients by gas chromatograph. The results show that there were only $\mathrm{CO}_{2}, \mathrm{O}_{2}$ and $\mathrm{N}_{2}$ and it indicates that the organic matter was thoroughly oxidized to $\mathrm{CO}_{2}$ and $\mathrm{H}_{2} \mathrm{O}$.

The effect of pressure to treatment of wastewater by SCWO. In order to study the effect of pressure, the SCWO experiments of the wastewater were conducted at temperature $(T)$ of $853 \mathrm{~K}$ and constant oxidation coefficient $(\alpha)$ of 2.5 , the reaction time $(t)$ of $60 \mathrm{~s}$ and the pressure $(P)$ were changed from $25 \mathrm{MPa}$ to $29 \mathrm{MPa}$. Each experiment repeated three times and the average result was plotted as the final value. The results are showed in Fig. 3.



Fig.3 Influences of pressure on treatment effeciency of biochemical sludge from coal gasification wastewater

As we can see from the Fig. 3, the changes of the pollutant removal rate were unconspicuous with the changes of the pressure. It was same with our previous experimental results[6]. Therefore, we do not need to improve the operating pressure to improve pollutant removal rate and we choose the pressure of $25 \mathrm{MPa}$ which is relatively low to be the appropriate operating pressure. 
The effect of constant oxidation coefficient to treatment of wastewater by SCWO. Considering that the demand for steel tubes is higher with the increase of the the temperature under the condition of supercritical water, we reduced the temperature by increasing the oxidation coefficient to improve the system efficiency. In order to study the effect of constant oxidation coefficient, the SCWO experiments of the wastewater were conducted at temperature $(T)$ of $823 \mathrm{~K}$ and the pressure $(P)$ of 25 $\mathrm{MPa}$, the reaction time $(t)$ of $60 \mathrm{~s}$ and constant oxidation coefficient $(\alpha)$ were changed from 1.5 to 3.5 . Each experiment repeated three times and the average result was plotted as the final value. The results are showed in Fig. 4.

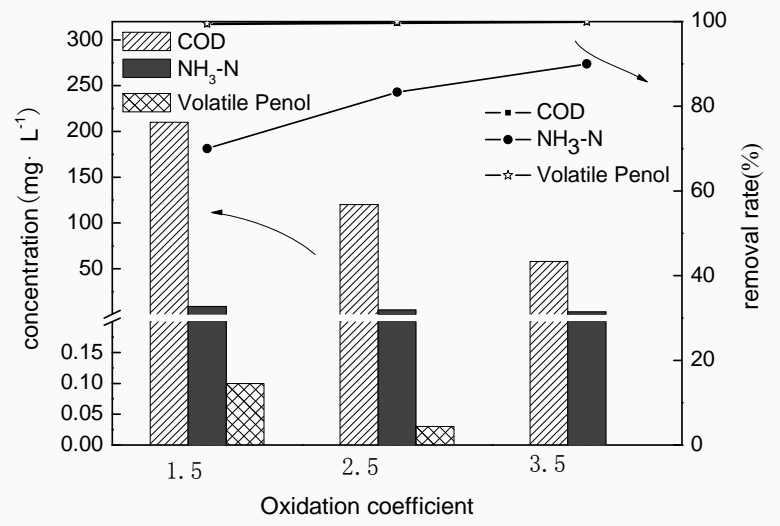

Fig. 4 Influences of oxidation coefficient on treatment effeciency of biochemical sludge from coal gasification wastewater

As we can see from the Fig. 3, the pollutant removal rate increased with the increase of oxidation coefficient. The COD, NH3-N and volatile phenol were $210,9,0.1 \mathrm{mg} / \mathrm{L}$ and the removal rate were $99.3 \%, 70 \%, 99.54 \%$ when the constant oxidation coefficient was 1.5. But when the constant oxidation coefficient changed to 3.5 , The COD reduced to $58 \mathrm{mg} / \mathrm{L}$, the $\mathrm{NH} 3-\mathrm{N}$ reduced to $3 \mathrm{mg} / \mathrm{L}$, the volatile phenol is below the test line. The effect of the oxidant is more and more obvious with the increase of the concentration, for that the concentration of $\cdot \mathrm{OH}$ is increase with the increase of the concentration of the oxidant.

The effect of constant oxidation coefficient to treatment of wastewater by SCWO. In order to study the effect of the reaction time $(t)$, the SCWO experiments of the wastewater were conducted at temperature $(T)$ of $823 \mathrm{~K}$ and constant oxidation coefficient $(\alpha)$ of 3.5 , the pressure $(P)$ of $25 \mathrm{MPa}$ and the reaction time $(t)$ were changed from $50 \mathrm{~s}$ to $90 \mathrm{~s}$. Each experiment repeated three times and the average result was plotted as the final value. The results are showed in Fig. 5.



Fig.5 Influences of reaction time on treatment effeciency of biochemical sludge from coal gasification wastewater

As we can see from the Fig.5, The COD and NH3-N removal rate were changed from 99.68\%, $80 \%$ to $99.8 \%, 90 \%$ when the reaction time changed from $30 \mathrm{~s}$ to $60 \mathrm{~s}$. But when the reaction time 
changed from $60 \mathrm{~s}$ to $90 \mathrm{~s}$, the change of the COD and NH3-N removal rate were not obvious. The results show that the degradation of COD and NH3-N happened at the first $60 \mathrm{~s}$ and it changed a little after that.

\section{Conclusions}

(1) The change of temperature, constant oxidation coefficient, reaction time has a great influence on the removal rate of the COD and NH3-N. The increase of the temperature, constant oxidation coefficient, reaction time would significantly improve the removal rate of the COD and NH3-N, but the influence of the change of the pressure is not obvious.

(2)For a biochemical sludge, the COD and NH3-N in effluent were 42 and $5 \mathrm{mg} \cdot \mathrm{L}^{-1}$, respectively, and the concentration of volatile phenol was below the limit of detection when treated at $873 \mathrm{~K}, 25$ $\mathrm{MPa}$, oxidation ratio of 3.5 and reaction time of $60 \mathrm{~s}$. The effluent quality can reach the national wastewater discharge standard I of GB 8978-1996.

In conclusion, this study provides a new idea for the treatment of refractory sludge containing high concentration of tar and phenol and the following work is to study the system energy consumption, process design, economic evaluation and so on.

\section{References}

[1] R. Kumar, and P. Pal: Environmental Technology, 35 (2014), 2018-2027.

[2] P. A. Marrone: Journal of Supercritical Fluids, 79 (2013), 283-288.

[3] W. J. Gong, F. Li, and D. L. Xi: Environmental Engineering Science, 26 (2009), 131-136.

[4] J. L. Yu, and P. E. Savage: Applied Catalysis B-Environmental, 28 (2000), 275-288.

[5] J. Bonin, I. Janik, D. Janik, and D. M. Bartels: Journal Of Physical Chemistry A, 111 (2007), 1869-1878.

[6] Y. Z. Wang, S. Z. Wang, Y. Guo, D. H. Xu, Y. M. Gong, X. Y. Tang, and J. Zhang: Environmental Progress \& Sustainable Energy, 33 (2014), 1258-1265. 